\title{
Gerai Kopi di Jakarta dalam Adaptasi Kehidupan Baru
}

\author{
Pandu Adi Cakranegara \\ Universitas Presiden, Jababeka Education Park, Bekasi, West Java, Indonesia 17530 \\ pandu.cakranegara@president.ac.id
}

ARTICLE INFO (8 pt)

Article history:

Received: July 07, 2020

Reviewed: August 10, 2020

Accepted: October 20, 2020

Published: December 21, 2020

Keyword: New Normal, coffee shops, Jakarta

Kata kunci: Adaptasi Kehidupan Baru, gerai kopi, Jakarta

\section{ABSTRACT}

Covid 19 pandemic in Jakarta forced individuals living in Jakarta to live New Normal. Restaurants, food stalls and various eating places were hit hard by this situation. This study tries to look at the impact of Covid 19 and what cafe owners are doing to be able to adapt in the New Life Adaptation Era. The method used was observation and interviews with 50 coffee cafes in various regions in Jakarta. From the results of interviews and observations there are several things that can be concluded. Coffee shops need to take new and unusual steps before the pandemic in order to survive. The steps found in this research are to build personal relationships with customers, cost savings, and focus on online marketing.

\begin{abstract}
ABSTRAK
Dengan adanya pandemi Covid 19 di Jakarta maka individu yang tinggal di Jakarta perlu melaksanakan Adaptasi Kehidupan Baru. Restoran, warung dan berbagai tempat makan mengalami pukulan yang keras oleh situasi ini. Penelitian ini mencoba melihat dampak Covid 19 dan apa yang dilakukan oleh para pemilik kafe untuk dapat beradaptasi di Era Adaptasi Kehidupan Baru. Metode yang digunakan adalah observasi dan wawancara terhadap 50 kafe kopi yang ada di berbagai daerah di Jakarta. Dari hasil wawancara dan observasi ada beberapa hal yang dapat disimpulkan. Gerai kopi perlu mengambil langkah-langkah yang baru dan yang tidak biasa dilakukan di era sebelum pandemi agar tetap dapat bertahan hidup. Langkah-langkah yang ditemukan dalam penelitian ini adalah dengan membangun hubungan personal dengan pelanggan, penghematan kos, dan fokus pada pemasaran daring.
\end{abstract}

\section{Pendahuluan}

\section{A. Pandemi dan Akibatnya bagi gerai kopi di Jakarta}

Di Jakarta terdapat lebih dari 3.000 kedai kopi yang tersebar di berbagai wilayah di Jakarta (Perindustrian, 2016). Berdasarkan data dari Kementerian Perindustrian fenomena ini terjadi di seluruh Indonesia. Namun demikian tidak dapat dipungkiri Jakarta mengalami pertumbuhan tertinggi dalam penambahan jumlah gerai kopi (Gunawan, 2018). Hal ini salah satu didorong oleh disposable income individu Jakarta yang lebih tinggi dari daerah terutama untuk gaya hidup.

Gerai kopi di Jakarta dapat digolongkan menjadi beberapa tipe. Kedai kopi dapat dibagi berdasarkan kedai kopi di mana konsumen dapat makan di tempat atau kedai kopi yang lebih menyajikan kopi untuk dibawa. Selain itu kedai kopi dapat dibagi berdasarkan jumlah cabang yaitu kedai kopi

W : http://e-journal.polnes.ac.id/index.php/edutourism/

E : jurnal_edutourism@polnes.ac.id 
yang telah memiliki banyak cabang dan kedai kopi independen. Kedai kopi juga dapat dibagi berdasarkan segmen pelanggannya yaitu kedai kopi yang menengah atas dan kedai kopi yang ekonomis.

\section{B. Aglomerasi Kedai Kopi di Jakarta}

Ada gula ada semut. Ini adalah peribahasa yang dapat digunakan untuk menjelaskan kenapa kedai kopi dengan tipe tertentu mengelompok di tempat-tempat tertentu. Daerah Jakarta sendiri terbagi menjadi berbagai zonasi (Ahmad, 2002). Di daerah seperti Sudirman dan Kuningan merupakan daerah bisnis dengan banyak kantor. Sementara itu di Jakarta Utara merupakan daerah pemukiman penduduk kelas menengah ke atas. Di Jakarta Selatan merupakan daerah yang lebih bervariasi di mana terdapat beberapa perkantoran dan juga perumahan penduduk, serta turisme. Kedai-kedai kopi melihat pola-pola ini dan menyesuaikan diri dengan tipe konsumen di sekitarnya.

Di daerah Sudirman dan Kuningan kedai kopi menyasar orang kantoran. Kedai-kedai kopi di daerah ini terletak di dekat gedunggedung seperti Astra Tower, Indofood Tower, Menara BNI, Bundaran Hotel Indonesia. Sementara itu di daerah Menteng di mana banyak wisatawan asing maka kedai kopinya cenderung menyajikan kedai kopi di tempat dengan menyajikan makanan berat dan menu khas Indonesia.

Di daerah Kemang yang merupakan tempat domisili ekspatriat banyak kedai kopi menengah ke atas dengan harga yang premium dan menyajikan makanan barat. Di dekat daerah Kemang yaitu daerah Cipete Raya kedai kopi yang ada di sana merupakan kedai kopi kelas menengah dengan harga yang lebih terjangkau yang menjadikan anak muda sebagai segmen pelanggannya.

Di Jakarta Utara kedai kopi yang ada adalah kedai kopi yang menyajikan berbagai makanan fusion dan memiliki tempat yang didesain khusus untuk berswafoto. Kedaikedai kopi ini mengandalkan keunikan desain sebagai salah satu daya tarik dengan harga yang berada di segmen menengah.

Di Jakarta Barat kedai kopi yang ada adalah kedai kopi yang ekonomis dan kedai kopi yang dibawa pergi. Hal ini dikarenakan banyaknya jumlah kampus di Jakarta yang berada di daerah Jakarta Barat sehingga daya beli konsumennya lebih rendah daripada konsumen di Jakarta Utara yang merupakan perumahan menengah ke atas atau daerah Jakarta Pusat yang merupakan pegawai kantoran.

\section{Review Tinjauan Pustaka}

\section{A. Kedai Kopi sebelum Pandemi}

Menurut Poernomo et al (2019) kodai kopi dapat digolongkan ke dalam industri kreatif. Dan salah satu untuk memperkenalkannya adalah dengan menggunakan branding untuk menciptakan suatu identitas yang dikenal konsumen. Aryani (2019) secara khusus meneliti tentang sensory branding terutama penggunaan desain ruangan yang menarik, penataan produk dan visual untuk membuat kedai kopi menjadi menarik. Ini adalah salah satu pendekatan yang digunakan kedai-kedai kopi terutama untuk kedai kopi yang menyasar segmen menengah ke atas dengan usia 20 hingga 40 an tahun.

Hal lain yang menentukan kesuksesan gerai dengan tema tertentu (themed stall) menurut Reynold et al (2007) adalah kos, retensi pelanggan dan kepuasan pegawai. Kedai kopi dengan tipe dan strategi seperti ini adalah kedai kopi yang disebut sebagai kedai kopi generasi ketiga (2018). Generasi kopi ketiga ini kemudian akan berubah lagi menuju ke tren generasi kopi keempat yang disebut generasi kopi to go. Pada gelombang in kopi sudah merupakan gaya hidup dan orang meminum kopi sambil beraktivitas.

\section{B. Pengaruh Pandemi Covid 19 terhadap Bisnis Hotel, Restoran dan Kafe}

Baker et al (2020) menyatakan bahwa hal yang paling terasa dari pandemi Covid 19 adalah munculnya ketidakpastian. Ketidakpastian ini dirasakan pada pasar modal dan bisnis riil baik besar maupun kecil. Fernandes (2020) menyatakan bahwa bisnis yang terkait dengan mobilisasi individu dan berkumpulnya individu akan terpukul berat. Ini berarti bisnis seperti penerbangan, hotel dan restoran serta kafe menjadi salah satu yang terkena dampaknya. 
Lumbanraja (2011) mengatakan bahwa sektor usaha kecil mikro dan menengah merupakan sektor penyokong ekonomi yang telah terbukti membawa Indonesia melalui berbagai krisis. Namun kali ini situasi tersebut berbeda karena baik usaha besar maupun kecil harus menutup pintunya dengan paksa karena pandemi.

Usaha kecil dengan segala keuletannya memiliki peluang untuk menjadi pendorong pemulihan ekonomi. Bartik et al (2020) meneliti bagaimana industri kecil di Amerika Serikat kembali buka dan berusaha menyesuaikan diri dengan Adaptasi Kehidupan Baru. Industri kecil ini yang diharapkan oleh pemerintah Amerika Serikat untuk dapat kembali menggerakkan roda perekonomian.

Demikian pula dengan Indonesia. Usaha kecil dan menengah memiliki peran penting dalam mulai menggerakkan roda perekonomian. Hapsari (2014) dalam penelitiannya menemukan kaitan yang signifikan antara perkembangan usaha mikro kecil dan menengah terhadap perekonomian kota.

Berdasarkan penelitian-penelitian terdahulu maka penelitian ini berusaha meneliti bagaimana usaha mikro kecil dan menengah dapat beradaptasi di kondisi yang baru. Penelitian ini mengkhususkan diri pada gerai kopi lokal sebagai salah satu bentuk usaha mikro kecil dan menengah. Peneliti meneliti langkah-langkah apa yang diambil para pengusaha lokal untuk dapat mempertahankan usaha di era Adaptasi Kehidupan Baru.

\section{Metodologi Penelitian}

Metode penelitian ilmiah terdiri dari penelitian kuantitatif, kualitatif dan metode campuran. Penelitian ini menggunakan metode kualitatif yaitu dengan observasi dan wawancara. Penelitian kualitatif menurut Birkinshaw et al (2011) membuat bisnis dapat kembali ke akarnya. Salah satu contoh hal tersebut adalah dengan kembali ke data primer. Dalam hal ini adalah bertanya dan mengobservasi perilaku para pebisnis dalam menjalankan bisnis.

Juliandi (2014) mengatakan bahwa penelitian dalam ranah ilmu sosial berbeda dengan ilmu alam dan teknik yang menghasilkan sebuah ciptaan baru yang spektakuler. Penelitian sosial menjawab masalah-masalah sosial yang dihadapi manusia. Pandemi Covid 19 merupakan masalah kesehatan namun konsekuensinya tidak hanya bagi orang yang sakit saja juga bagi orang yang sehat. Dengan adanya pembatasan sosial berskala besar maka bisnis harus beradaptasi. Di sini ilmu sosial berperan untuk membantu mencari jawaban atas masalah ini. Bagaimana adaptasi baru yang dapat dilakukan agar kehidupan masyarakat dapat berjalan kembali.

Dalam melakukan metode kualitatif yang paling penting adalah perencanaan terutama sebelum terjun ke lapangan (Eriksson, 2015). Penelitian ini menggunakan wawancara dengan pertanyaan yang telah disiapkan sebelumnya. Pertanyaan yang ditanyakan adalah pertanyaan eksploratif sehingga narasumber dapat menjawab sesuai dengan kondisi dan pendapatnya. Dowkin (2012) menyatakan bahwa jumlah responden untuk diwawancarai berkisar antara 5 hingga 50 . Angka ini hanya kisaran karena dalam memilih jumlah orang yang diwawancara ada beberapa hal lain yang perlu diperhatikan seperti keseragaman narasumber.

Bungin (2007) mengategorikan observasi menjadi tiga yaitu observasi partisipasi, observasi tidak terstruktur dan observasi kelompok. Observasi partisipasi yaitu ketika dalam proses observasi peneliti ikut serta dalam aktivitas narasumber, observasi tidak terstruktur yaitu observasi di mana peneliti melihat kondisi seorang narasumber dan aktivitas alami narasumber, dan ketiga observasi kelompok di mana observasi dilakukan terhadap sekelompok narasumber di lingkungan alami narasumber. Dari ketiga jenis observasi ini penelitian ini menggunakan observasi tipe kedua yaitu observasi tidak terstruktur.

Penelitian ini melakukan wawancara terhadap sepuluh pemilik kopi dan barista serta observasi terhadap lima puluh gerai kopi di berbagai daerah di Jakarta. Wawancara dilakukan dengan kondisi non formal dan hasil wawancara kemudian dicatat oleh peneliti. Dari hasil wawancara dan observasi tersebut peneliti kemudian menarik kesimpulan. 


\section{Hasil dan Diskusi}

Berdasarkan hasil wawancara dan observasi maka dapat diambil kesimpulan halhal yang dilakukan oleh para pemilik gerai kopi dalam upayanya bertahan untuk menghadapi pandemi Covid 19.

\section{A. Hubungan yang Lebih Personal dengan Konsumen}

Penelitian dari Octaviani (2013) terhadap faktor yang paling mempengaruhi retensi pembelian kopi atau alasan seseorang menjadi pelanggan suatu kafe adalah empati. Ini berarti hubungan antara konsumen kedai kopi dan kedai kopi yang diwakili oleh barista dan server kopi. Dari observasi yang dilakukan oleh penulis terhadap kopi selama bulan Juni 2020 di 50 kafe di Jakarta terjadi penurunan dalam jumlah pengunjung yang drastis. Ini terlihat dari perbandingan jumlah bangku dengan konsumen yang duduk. Bahkan dengan model Adaptasi Kehidupan Baru di mana satu meja kopi yang semula diperuntukkan untuk empat orang kini hanya dapat diduduki oleh dua orang, masih banyak meja yang kosong.

Ini berarti kesibukan para pegawai kopi seperti barista dan server pun menjadi turun. Ini adalah saatnya untuk membangun hubungan yang lebih personal terutama dengan konsumen yang terus datang ke kedai kopi pada saat AKB. Tugas barista dan server yang dahulu fokus pada menyediakan kopi karena banyaknya pengunjung kini dapat dialokasikan untuk membangun hubungan untuk menciptakan nilai pelanggan yang lebih tinggi. Hal ini juga didukung oleh penelitian dari Reynold et al (2007) yang menemukan bahwa pegawai sebuah gerai mempunyai peran penting dalam meningkatkan produktivitas suatu gerai.

\section{B. Efisiensi Kos}

Efisiensi kos adalah hal yang perlu segera dilakukan terutama ketika pendapatan turun. Dari hasil penelitian Mhlangga (2018) bahwa di negara berkembang adalah efisiensi kos memungkinkan restoran memberikan barang lebih value for money bagi konsumen dan akan mendorong penjualan.

\section{Efisiensi Kos dengan Memotong Rantai Pasok}

Salah satu cara efisiensi kos adalah dengan membangun rantai pasok yang lebih terpadu. Fromm et al (2006) meneliti tentang hubungan antara petani kecil di Honduras dengan rantai pasok penjualan dari bijih kopi hingga menjadi kopi siap minum di tangan konsumen. Kondisi di Indonesia memiliki beberapa kemiripan dengan Honduras. Salah satunya adalah pada ukuran lahan yang dikelola petani kopi. Di Indonesia petani mengelola lahan yang kecil dan di industri pertanian yang memerlukan skala ekonomis untuk berkembang (Madden, 1967) maka ini adalah suatu tantangan bagi petani. Dengan kecilnya luas lahan maka kos petani menjadi tinggi dan dengan harga yang ditentukan oleh harga pasar komoditas mengakibatkan keuntungan petani menjadi rendah (Hidayah et al, 2013).

Fromm et al (2006) menyarankan agar petani menjual langsung ke pemilik kafe atau sebaliknya para pemilik kafe membeli langsung dari petani. Hal ini sangat bisa dilakukan di Indonesia karena dari hasil wawancara rata-rata harga kopi robusta yang dibeli pemilik kafe dari pedagang kopi berada di kisaran Rp. 100.000 sementara harga di petani hanya pada kisaran Rp 18.000 hingga Rp. 20.000. Efisiensi dalam rantai pasok dapat dilakukan melihat besarnya perbedaan harga dari hulu hingga hilir.

\section{Efisiensi Kos dengan Variasi Produk}

Gerai kopi terutama gerai kopi menengah ke atas sering menyediakan berbagai jenis kopi internasional. Dari hasil wawancara terungkap hal ini dilakukan untuk menambah kesan modern dan mewah padak gerai kopi. Jadi penyediaan varian bijih kopi asing ini bukan karena semata permintaan dari pelanggan. Menurut salah satu pemilik kedai kopi pelanggan kebanyakan tidak tahu mengenai varian bijih kopi dan meminta saran pada barista.

$\begin{array}{cccc}\text { Penelitian } & \text { dari } & \text { Sharma } & \text { (2009) } \\ \text { menunjukkan } & \text { bahwa } & \text { restoran } & \text { dapat }\end{array}$ menghemat biaya produksi dengan menggunakan bahan baku lokal. Hal ini juga dapat diterapkan pada gerai kopi yaitu dengan memperbanyak bijih kopi lokal dan mengurangi bijih kopi asing untuk sementara 
waktu. Bijih kopi lokal pun memiliki harga yang lebih murah.

\section{E. Efisiensi Kos Dengan Diskriminasi Harga}

Diskriminasi harga tipe kedua yaitu ketika perusahaan tidak tahu preferensi konsumen dan berusaha memaksimalkan pendapatan perusahaan maka perusahaan menyediakan berbagai paket untuk berbagai pelanggan (Bade et al, 2019). Salah satu yang telah dilakukan gerai kopi adalah dengan menjual produk dalam paket seperti beli paket isi dua, paket isi tiga, bahkan kopi dalam bentuk literan. Hal ini merupakan strategi diskriminasi harga tipe dua yang sebenarnya sedang dilaksanakan oleh pemilik kedai kopi.

Menjual produk dengan jumlah yang besar dan dengan harga diskon akan menurun pendapatan per unit tetapi di saat krisis karena pandemi ini justru dapat mendobrak pendapatan gerai kopi. Konsumen yang tidak bisa leluasa pergi ke luar lebih menyukai membeli dalam jumlah yang besar karena lebih praktis dan juga lebih murah.

\section{F. Strategi Pemasaran berbasis Media}

Pandemi kali ini membawa krisis yang berbeda. Individu harus dijauhkan secara fisik dari satu sama lain namun individu-individu dapat tetap terhubung dengan adanya internet. Kirtis et al (2011) menemukan bahwa investasi pada pemasaran di saat krisis adalah salah satu faktor penentu perusahaan dapat bertahan melewati krisis. Penelitian Kirtis et al (2015) juga menyarankan perusahaan untuk beralih ke pemasaran daring dan terutama media sosial karena ini adalah bentuk pemasaran yang lebih efisien dan efektif.

Notta et al (2015) meneliti bagaimana para pemimpin perusahaan di Yunani pada saat krisis. Dari hasil penelitiannya para pengusaha di Yunani beralih ke pemasaran daring dan terus memperkuat pemasaran walaupun penjualan turun. Karena kos pemasaran daring yang lebih rendah maka perusahaan dapat tetap mempertahankan capaian target audiensinya dengan biaya yang lebih rendah.

Di Indonesia salah satu bentuk pemasaran yang unik terutama bagi restoran dan gerai kopi adalah adanya ojek daring. Ilham (2018) menemukan bahwa dengan beriklan pada layanan ini ternyata dapat meningkatkan loyalitas konsumen. Penggunaan promosi di aplikasi pengantaran daring berdasarkan temuan dari Nadif (2019) merupakan strategi yang efektif bagi usaha mikro kecil dan menengah. Karena itu gerai kopi dapat memaksimalkan untuk beriklan di aplikasi layan antar daring seperti Go Food dan Grab Food.

\section{Kesimpulan}

Peneliti Michael Porter (2008) mengatakan bahwa untuk memenangkan persaingan suatu bisnis memerlukan competitive advantage. McGrath (2013) mengatakan era competitive advantage sudah berakhir dan kini saatnya bisnis yang cepat akan mengalahkan bisnis yang lebih lambat. Namun kondisi pandemi Covid 19 membuktikan pendapat Darwin (2010) bahwa bukan yang lebih kuat yang akan bertahan melainkan siapa yang dapat beradaptasi.

Penelitian ini menunjukkan bahwa gerai kopi yang termasuk dalam usaha kecil dan menengah bertahan dengan menggunakan cara-cara baru yang tidak dipraktikkan sebelumnya. Ukuran bisnis yang kecil tidak menjadi penghalang tetapi bisa menjadi kekuatan karena tidak perlu berbagai keributan administratif dalam menerapkan perubahan.

Penelitian selanjutnya dapat melihat kondisi gerai kopi yang menerapkan perubahan-perubahan ini, apakah berhasil dan sesuai harapan. Saat ini penelitian ini dapat digunakan untuk menjadi salah satu alternatif untuk bertahan di era Adaptasi Kehidupan Baru.

\section{References}

[1] Ahmad, A., 2002. Re-desain Jakarta: tata kota tata kita, 2020. Kotakita Press.

[2] Aryani, D. I. (2019). Tinjauan Sensory Branding dan Psikologi Desain Kedai Kopi Kekinian Terhadap Perilaku Konsumen (Studi Kasus: Mojo Coffee). Waca Cipta Ruang: Jurnal Ilmiah Desain Interior, 5(1), 330-336.

[3] Bade, Robin, and Michael Parkin. Essential foundations of economics. Pearson Education, 2019. 
[4] Baker, S. R., Bloom, N., Davis, S. J., \& Terry, S. J. (2020). Covid-induced economic uncertainty (No. w26983). National Bureau of Economic Research.

[5] Bartik, A.W., Bertrand, M., Cullen, Z.B., Glaeser, E.L., Luca, M. and Stanton, C.T., 2020. How are small businesses adjusting to covid-19? early evidence from a survey (No. w26989). National Bureau of Economic Research.

[6] Birkinshaw, J., Brannen, M.Y. and Tung, R.L., 2011. From a distance and generalizable to up close and grounded: Reclaiming a place for qualitative methods in international business research.

[7] Bungin, M. Burhan. 2007. Penelitian Kualitatif: Komunikasi, Ekonomi, Kebijakan Publik, dan Ilmu Sosial Lainnya. Jakarta: Kencana Prenada Media Group.

[8] Darwin, C., 2010. The works of Charles Darwin, Volume 16: The origin of species, 1876. NYU Press.

[9] Dworkin, S.L., 2012. Sample size policy for qualitative studies using in-depth interviews.

[10] Eriksson, P. and Kovalainen, A., 2015. Qualitative methods in business research: A practical guide to social research. Sage.

[11] Fernandes, N., 2020. Economic effects of coronavirus outbreak (COVID-19) on the world economy. Available at SSRN 3557504 .

[12] Fromm, I. and Dubon, J.A., 2006, October. Upgrading and the value chain analysis: The case of small-scale coffee farmers in Honduras. In Conference on International Agricultural Research for Development (pp. $1-7)$.

[13] Gunawan, E. J. M. (2018). Industri kopi Indonesia dan Third Wave Coffee Culture.

[14] Hapsari, P.P., Hakim, A. and Noor, I., 2014. Pengaruh Pertumbuhan Usaha Kecil Menengah (UKM) terhadap Pertumbuhan Ekonomi Daerah (Studi di Pemerintah Kota Batu). Wacana Journal of Social and Humanity Studies, 17(2), pp.88-96.

[15] Hidayah, I., \& Susanto, A. N. (2013). Economies of scale and allocative efficiency of rice farming at West Seram Regency, Maluku Province, Indonesia. Asian economic and financial review, 3(5), 624

[16] Ilham, R., 2018. Improve quality of e-loyalty in online food delivery services: a case of Indonesia. Journal of Theoretical and
Applied Information Technology, 96(15), pp.4760-4769.

[17] Juliandi, A. and Manurung, S., 2014. Metodologi Penelitian Bisnis, Konsep dan Aplikasi: Sukses Menulis Skripsi \& Tesis Mandiri. Umsu Press.

[18] Kirtiş, A.K. and Karahan, F., 2011. To be or not to be in social media arena as the most cost-efficient marketing strategy after the global recession. Procedia-Social and Behavioral Sciences, 24, pp.260-268.

[19] Lumbanraja, P., 2011. Bersama UKM membangun ekonomi rakyat dan lingkungan hidup.

[20] Madden, J. P. (1967). Economies of size in farming. Government Printing Office: Washington.

[21] McGrath, R.G., 2013. The end of competitive advantage: How to keep your strategy moving as fast as your business. Harvard Business Review Press.

[22] Mhlanga, O., 2018. Factors impacting restaurant efficiency: a data envelopment analysis. Tourism Review.

[23] Nadif, A.S., 2019. Strategi Pemasaran Online Food Delivery Grab Food Pada Wirausaha (Study Kasus Kedai Mie Bajak Pangarangan Sumenep) (Doctoral dissertation, Universitas Wiraraja).

[24] Notta, O. and Vlachvei, A., 2015. Changes in marketing strategies during recession. Procedia Economics and Finance, 24, pp.485-490.

[25] Octaviani, N., 2013. Pengaruh Kualitas Pelayanan Terhadap Kepuasan Pelanggan Kafe Kopi Miring Semarang. Jurnal Ekonomi Manajemen.

[26] Perindustrian, K., 2016. Siaran Pers: Produksi Kopi Indonesia Terbesar Ketiga Dunia [internet]. Jakarta (ID):[diunduh pada 29 Maret 2017]. Tersedia pada: http://www. kemenperin. go. id/artikel/6611/ProduksiKopi-Nusantara-Ketiga-Terbesar-Di-Dunia.

[27] Poernomo, D., Izzah, L., Sulistiyono, S.T., Rochwulaningsih, Y., Handayani, T., Handini, Y.D., Wahjuni, S., Purwowibowo, P., Karyadi, H., Suryawati, D. and Sisbintari, I., 2019. Industri Kreatif Kafe Kopi: Analisis Pemangku Kepentingan \& Prospek

[28] Porter, M.E., 2008. The five competitive forces that shape strategy. Harvard business review, 86(1), pp.25-40. 
[29] Reynolds, D. and Biel, D., 2007. Incorporating satisfaction measures into a restaurant productivity index. International Journal of Hospitality Management, 26(2), pp.352-361.
[30] Sharma, A., Gregoire, M.B. and Strohbehn, C., 2009. Assessing costs of using local foods in independent restaurants. Journal of Foodservice Business Research, 12(1), pp.55-71. 